\title{
A Brief Perspective on the Use of Bio-inoculants in Horticulture
}

Bandi Arpitha Shankar

Acharya N G Ranga Agricultural University, Tirupati-517502, Andhra Pradesh

\begin{abstract}
Soil is a treasure trove of microbial variety, and bio-inoculants have the potential to improve the performance of horticultural crops under biotic and abiotic stress by boosting soil microbial diversity. Bio-inoculants are being developed to increase the diversity of soil microbes. The combined effects of bio-inoculants, on the other hand, result in the expansion of vegetation in the surrounding environment. Previous study on arbuscular mycorrhizal fungus has shown the existence of agronomic and biochemical characteristics in horticultural crop species (AMF). Through the development of enhanced technologies for the analysis of RNA or DNA from soil, we may acquire a deeper knowledge of the microbiological diversity and functions of the planet, which are difficult to find using traditional societal approaches. It is not possible to uncover a full database of purposeful genetics, which includes both soil microorganisms and deliberate genetics. This is true for almost every soil type or circumstance. As a result of this review, this study offers suggestions for the use of bio-inoculants, the benefits of doing so, regular research strategies, and long-term research directions.
\end{abstract}

Keywords: Biodiversity, Fruits, Flowers, Metagenomics, Soil, Vegetables

\section{Introduction}

Plant-important microorganisms are studied for their nutrient acquisition, biocontrol, and pest and sickness growth promotion, and have been used as biofertilizers and biocontrol components in agricultural production for more than three years. Indian researchers have developed and employed a variety of microbiological compositions that are either stressor-free or include a mixture of stressors [1-5]. The success of a microbial bio inoculant in the agricultural field is governed by a variety of factors, not only the microorganism's capacity to produce it [6-12]. Despite the fact that only a few species have been studied so far, our current knowledge of their capacities, ecological adaptations, many interactions, and possible positive features of bio-inoculants in plants is 
restricted [13-27]. The majority of medical research on the microbiome focuses on identifying and characterizing bacteria that produce eukaryotic bio-inoculants for use in human medicine. Several scenarios still need thorough metagenomic investigations of collected plant microbiomes [28-36]. As a consequence, the normal microbiome component of each crop species is yet unknown. While certain microorganisms that interact with plants are thought to be harmful, a large number of bacteria that inhabit plant markets may demonstrate neutral or even positive traits at times [37-50]. There may be no easily available simple components or other bio-inoculants for bacteria conducting the most fundamental function on the site. A metagenomic analysis aiming at identifying and functionally characterising these essential microorganisms, according to the researchers, may give insight into their function as well as their connections with other bacteria in the microenvironment [51-70].

Furthermore, it seems that the horizontal transfer of all Proteobacteria's plant-critical genetics has been discovered. Furthermore, it is recognised that a crop's genotype, tissue/plant body organ, abiotic environment, and developmental stage all have an influence on its microbiome framework [71-80]. Changes/imbalances in the microbiome framework of the human body may lead to disease, while changes in the microbiome composition of plant parts can lead to vulnerability to stress and illness [81-87]. There is currently little information on the compatibility or incompatibility of the released microorganism with indigenous bio-inoculants. Encouragement of marginal and uneven plant growth, biocontrol of pests, and disease's extra output may be addressed, resulting in an increase in overall production. This adds to our understanding of how the makeup of the microbiome changes as a result of the introduction of bio-inoculants.

Similarly, modifying the method for soil microbial testing in gardening and making the microbiological blueprint of each harvested species available to scientists and regional politicians may help them correctly advocate for environmentally friendly and other problems. Bio-inoculants may remain a viable method of encouraging plant growth and output while also enhancing plant resistance to abiotic stressors. It is important to remember that variable dynamics, a complex of raw materials utilised in their formation, and a heterogeneous mix of components in the completed device may all contribute to the success of a bio-inoculant by providing a distinct sequence of actions for each. The issue is worsened greatly by plant longevity, the use of bio-inoculants, and the availability of a varied range of components in the increasing bio-inoculant spectrum. Two products produced by two different plant species, for example, might be considered to be part of 
the same training. However, the effects of their actions and how they carry them out may vary. In addition, the flip scenario is conceivable; the related product may have unexpected repercussions when applied to plant life that is not the original plant life [88].

Rouphael and Coltion must adapt to harsh environmental conditions due to their sessile nature; many of these techniques are crucial for survival. Any bio-comfort inoculant is the result of the synergistic impact of numerous large bioactive substances, rather than a single combination. These strategies, if implemented quickly, strive to establish a defensive reaction alongside matter in response to environmental changes that have the potential to permanently harm plant growth. The potential trade-off between growth and acclimation metabolisms imposes a physical cost on plant life, as energy and nutrients that would otherwise be utilised for growth are rerouted to stressresponsive systems, and newspapers are created to maintain these processes. Farmers' experiences, technological developments, climatic change, and scientific understanding have all contributed to the growth of abiotic pressures throughout history. Agronomic management has resulted in increased resistance to abiotic stresses. The number of the appropriate cultivar, the ideal acquisition time, the sowing density, and, of course, the amount of water and fertiliser used are all crucial aspects to consider. Crop production in a protected environment is a farming practise used to safeguard plants from harsh environmental conditions. It is largely useful for producing vegetables and flowers in less-than-ideal conditions, mostly via temperature, soothing, and maybe air composition regulation. Soilless cultivation is another agronomical approach that is often employed in vegetable plant production $[88,90]$.

\section{Conclusions and Future Prospects}

Plant bio-inoculants are chemicals or microbes that are introduced into a plant's environment with the goal of enhancing plant growth and production while mitigating the negative effects of abiotic stressors. These chemicals or microbes can be either organic or inorganic in nature and can be either beneficial or harmful to the plant. Natural plant hormones, trace amounts of organic plant hormones, minerals, nutritional supplements, amino acids, poly oligosaccharides, and amino acids generated from plant hormones are only a few of the most well-known constituents. It is crucial to emphasise, however, that the action of bio-inoculants should not be dependent on the nutritional content of the meal or even the presence of commonly recognised plant hormones in the diet. Even now, the systems induced by bio-inoculants remain mysterious, and study on them is still ongoing. 
According to the findings of a recent research, high-throughput and omic technologies phenotyping seem to be useful approaches for monitoring the activity of bio-inoculants and hypothesising a training strategy for them. It is possible that they will have an influence on plant physiology and metabolism as a consequence of enhancing the soil conditions. To maximise the efficiency with which plants utilise water and nutrients, it is required for them to be in a position where they may exert control over specific molecular processes. Additionally, they may aid in the promotion of plant growth and the maintenance of a healthy balance between abiotic and biotic stressors by raising the primary and secondary metabolic rates of the plant. All of the points of view represented in this debate are focused on the use of these items for their original function and as sustenance under stressful conditions, rather than the capacity of these items to have a therapeutic effect on their own.

As a result, bio-inoculants are often referred to as these key classes when discussing them. Bacteria, yeasts, filamentous fungus, and microalgae have all been included into the studies of this group of scientists. In order to maintain their integrity, they must be maintained apart from other organic substances such as soil, plants, water, composted manures, and even specific animal waste, among other things. These organisms are introduced to the field in order to boost the yield of crops by enhancing metabolic activity inside the soil. They improve nutrient absorption by the plant by increasing stress hormones such as cytokinins and other hormones; in addition, they promote plant tolerance to abiotic stressors and create volatile organic compounds (VOCs), which may have an immediate impact on vegetation. According to the findings of the research, the solubilization and nitrogen fixation of nutrients by Rizobacteria that promote plant development (PGPR) have been shown to increase plant responses to abiotic stresses by revitalising the physical, biological, and chemical components of the plant's life cycle, which in turn increases plant responses to abiotic stresses. The favourable benefits are attributed to the microorganisms that develop a protective biofilm on the root site, boosting the quantity of material and fluid swallowed as a result of their presence.

1. Yadav, V.; Kaushik, P.; others Phytochemicals against COVID-19 and a Gap in Clinical Investigations: An Outlook. Indian Journal of Biochemistry and Biophysics (IJBB) 2021, 58, 403-407. 
2. Yadav, V.; Jha, R.; Kaushik, P.; others Biochemical Composition of Potato Biowaste of Popular North Indian Cultivars. Indian Journal of Biochemistry and Biophysics (IJBB) 2021, 58, 100-104.

3. Yadav, V.K.; Jha, R.K.; Kaushik, P.; Altalayan, F.H.; Al Balawi, T.; Alam, P. Traversing Arbuscular Mycorrhizal Fungi and Pseudomonas Fluorescens for Carrot Production under Salinity. Saudi Journal of Biological Sciences 2021, 28, 4217-4223.

4. Yadav, A.; Saini, I.; Kaushik, P.; Ansari, M.A.; Khan, M.R.; Haq, N. Effects of Arbuscular Mycorrhizal Fungi and P-Solubilizing Pseudomonas Fluorescence (ATCC-17400) on Morphological Traits and Mineral Content of Sesame. Saudi Journal of Biological Sciences 2021, 28, 2649-2654.

5. Sharma, M.; Saini, I.; Kaushik, P.; Al Dawsari, M.M.; Al Balawi, T.; Alam, P. Mycorrhizal Fungi and Pseudomonas Fluorescens Application Reduces Root-Knot Nematode (Meloidogyne Javanica) Infestation in Eggplant. Saudi Journal of Biological Sciences 2021.

6. Sharma, M.; Kaushik, P.; Chawade, A. Frontiers in the Solicitation of Machine Learning Approaches in Vegetable Science Research. Sustainability 2021, 13, 8600.

7. Sharma, M.; Kaushik, P. Vegetable Phytochemicals: An Update on Extraction and Analysis Techniques. Biocatalysis and Agricultural Biotechnology 2021, 102149.

8. Sharma, M.; Kaushik, P. Breeding for Root-Knot Nematode Resistance in Eggplant: Progress and Prospects. 2021.

9. Sharma, M.; Kaushik, P. Biochemical Composition of Eggplant Fruits: A Review. Applied Sciences 2021, 11, 7078. 
10. Sharma, M.; Kaushal, R.; Kaushik, P.; Ramakrishna, S. Carbon Farming: Prospects and Challenges. Sustainability 2021, 13, 11122.

11. Priyanka, V.; Kumar, R.; Dhaliwal, I.; Kaushik, P. Germplasm Conservation: Instrumental in Agricultural Biodiversity-A Review. Sustainability 2021, 13, 6743.

12. Malhi, G.S.; Kaur, M.; Kaushik, P. Impact of Climate Change on Agriculture and Its Mitigation Strategies: A Review. Sustainability 2021, 13, 1318.

13. Malhi, G.S.; Kaur, M.; Kaushik, P.; Alyemeni, M.N.; Alsahli, A.A.; Ahmad, P. Arbuscular Mycorrhiza in Combating Abiotic Stresses in Vegetables: An Eco-Friendly Approach. Saudi Journal of Biological Sciences 2021, 28, 1465.

14. .

15. Kumar, A.; Kaushik, P. Heat Stress and Its Impact on Plant Function: An Update. Preprints. 2021.

16. Kumar, A.; Kaushik, P. Advances and Milestones of Radish Breeding: An Update. Preprints. 2021.

17. Kesh, H.; Kaushik, P. Advances in Melon (Cucumis Melo L.) Breeding: An Update. Scientia Horticulturae 2021, 282, 110045.

18. Kaushik, P. Precision Vegetable Farming Technologies: An Update. Preprints. 2021.

19. Gupta, R.; Kaushik, P. Phyto-Potential of Allium Cepa and Allium Sativum. Preprints. 2021.

20. Gupta, R.; Kaushik, P. An Update on the Phyto-Potential of Allium cepa and Allium sativum. Preprints. 2021. 
21. Dhaliwal, S.K.; Salaria, P.; Kaushik, P. Pea Seed Proteins: A Nutritional and Nutraceutical Update. In Grain and Seed Proteins Functionality; IntechOpen, 2021.

22. Brar, N.S.; Sharma, S.P.; Kaushik, P. Visiting Potato from a Breeding Perspective: Accomplishments and Prospects. 2021.

23. Bijalwan, P.; Jeddi, K.; Saini, I.; Sharma, M.; Kaushik, P.; Hessini, K. Mitigation of Saline Conditions in Watermelon with Mycorrhiza and Silicon Application. Saudi Journal of Biological Sciences 2021.

24. Yadav, V.; Pandey, S.; Kaushik, P. A Brief Perspective on Japanese Eel (Anguilla Japonica Temminck \& Schlegel, 1846) an Indispensable Part of Japanese Culture. 2020.

25. Yadav, V.K.; Singh, R.; Jha, R.K.; Kaushik, P.; others Biochemical Variability of Eggplant Peel among Indian Cultivars. Indian Journal of Biochemistry and Biophysics (IJBB) 2020, 57, 634-637.

26. Vijeth, S.; Sreelathakumary, I.; Aiswarya, C.S.; Kaushik, P. Screening of Popular Indian Chili Pepper (Capsicum Annuum L.) Genotypes Against the Chili Leaf Curl Virus Disease. Plant Pathology Journal 2020, 19, 121-131.

27. Tarun, K.; Bhardwaj, K.; Kaushik, P.; others Effect of Soil Properties and Nutrient Status on Eucalyptus Tereticornis Based Agroforestry System in India. Effect of soil properties and nutrient status on Eucalyptus tereticornis based agroforestry system in India. 2020.

28. Singh, H.; Sethi, S.; Kaushik, P.; Fulford, A. Grafting Vegetables for Mitigating Environmental Stresses under Climate Change: A Review. Journal of Water and Climate Change 2020, 11, 1784-1797.

29. Saini, I.; Yadav, V.K.; Aggarwal, A.; Kaushik, P.; others Effect of Superphosphate, Urea and Bioinoculants on Zinnia Elegans Jacq. Indian Journal of Experimental Biology (IJEB) 2020, 58, 730-737. 
30. Saini, I.; Rani, K.; Gill, N.; Sandhu, K.; Bisht, N.; Kumar, T.; Kaushik, P.; others Significance of Arbuscular Mycorrhizal Fungi for Acacia: A Review. Pakistan Journal of Biological Sciences: PJBS 2020, 23, 1231-1236.

31. Saini, I.; Kumar, T.; Chauhan, J.; Kaushik, P. Acacia from a Breeding and Biotechnological Perspective: A Review. Pakistan Journal of Biological Sciences: PJBS 2020, 23, 13511356.

32. Saini, I.; Chauhan, J.; Kaushik, P. Medicinal Value of Domiciliary Ornamental Plants of the Asteraceae Family. Journal of Young Pharmacists 2020, 12, 3.

33. Saini, D.K.; Devi, P.; Kaushik, P. Advances in Genomic Interventions for Wheat Biofortification: A Review. Agronomy 2020, 10, 62.

34. Rajeev, K.; Bimlendra, K.; Shikha, Y.; Kaushik, P.; others Assessment of Genetic Diversity among Poplar (Populus Deltoides Marsh.) Clones from India Using RAPD Markers. Assessment of genetic diversity among poplar (Populus deltoides Marsh.) clones from India using RAPD markers. 2020.

35. Kumar, P.; Kaushik, P. Evaluation of Genetic Diversity in Cultivated and Exotic Germplasm Sources of Faba Bean Using Important Morphological Traits. BioRxiv 2020.

36. Kumar, A.; Sharma, V.; Jain, B.T.; Kaushik, P. Heterosis Breeding in Eggplant (Solanum Melongena L.): Gains and Provocations. Plants 2020, 9, 403.

37. Kesh, H.; Kaushik, P. Visiting Bitter Gourd (Momordica Charantia) from a Breeding Perspective: A Review. 2020.

38. Kesh, H.; Kaushik, P. Impact of Marker Assisted Breeding for Bacterial Blight Resistance in Rice: A Review. Plant Pathology Journal 2020, 19, 151-16. 
39. Kaushik, P.; Sandhu, O.S.; Brar, N.S.; Kumar, V.; Malhi, G.S.; Kesh, H.; Saini, I. Soil Metagenomics: Prospects and Challenges. In Mycorrhizal Fungi-Utilization in Agriculture and Industry; IntechOpen, 2020.

40. Kaushik, P.; Kumar, P.; Kumar, S.; others Enhancement of Chlorogenic Content of the Eggplant Fruit with Eggplant Hydroxycinnamoyl CoA-Quinate Transferase Gene via Novel Agroinfiltration Protocol. Pharmacognosy Magazine 2020, 16, 450.

41. Kaushik, P. Transcriptome Analysis of the Eggplant Fruits Overexpressing a Gene of Chlorogenic Acid Pathway. bioRxiv 2020.

42. Kaushik, P. Classification of Indian States and Union Territories Based on Their Soil Macronutrient and Organic Carbon Profiles. bioRxiv 2020.

43. Kaushik, P. Characterization of Cultivated Eggplant and Its Wild Relatives Based on Important Fruit Biochemical Traits. Pakistan Journal of Biological Sciences: PJBS 2020, 23, 1220-1226.

44. Dhaliwal, S.K.; Salaria, P.; Kaushik, P. Revisiting and Enlisting Important QTLs Identified in Frech Bean (Phaseolus Vulgaris L.): A Review. 2020.

45. CS, A.; Kaushik, P.; others Diallel Analysis of Chilli Pepper (Capsicum Annuum L.) Genotypes for Morphological and Fruit Biochemical Traits. Plants 2020, 9, 1.

46. Chauhan, J.; Yadav, V.K.; Sahu, A.P.; Jha, R.K.; Kaushik, P.; others Biosorption Potential of Alkali Pretreated Fungal Biomass for the Removal and Detoxification of Lead Metal lons. Journal of Scientific and Industrial Research (JSIR) 2020, 79, 636-639.

47. Chauhan, J.; Saini, I.; Singh, T.; Kaushik, P. A Brief Perspective on Acacia a Member of Family Leguminosae. 2020. 
48. Chauhan, J.; Saini, I.; Kaushik, P. Studies on the Biosorption Potential of Copper by Rhizopus Arrhizus Biomass. bioRxiv 2020.

49. Chauhan, J.; Yadav, V.; Saini, I.; Jha, R.; Tanwar, A.; Kaushik, P. Effect of Fungal Pretreatment on Solanum Nigrum L. Leaves Biomass Aimed at the Bioadsorption of Heavy Metals. 2020.

50. BRAR, N.; KAUSHIK, P.; DUDI, B. EFFECT OF SEED PRIMING TREATMENT ON THE PHYSIOLOGICAL QUALITY OF NATURALLY AGED ONION (ALLIUM CEPA L.) SEEDS. APPLIED ECOLOGY AND ENVIRONMENTAL RESEARCH 2020, 18, 849-862.

51. Brar, N.S.; Saini, D.K.; Kaushik, P.; Chauhan, J.; Kamboj, N.K. Directing for Higher Seed Production in Vegetables. Agronomy-Climate Change \& Food Security 2020, 55.

52. Brar, N.S.; Kumar, T.; Kaushik, P. Integration of Technologies under Climate Change for Profitability in Vegetable Cultivation: An Outlook. 2020.

53. Bharti, B.; Dubey, R.; Kumar, A.; Pal, L.; Kaushik, P. Understanding the Genetics of Important Traits in Quality Protein Maize (Zea Mays L.) by Line\$ $\backslash$ times\$ Tester Analysis. bioRxiv $\mathbf{2 0 2 0 .}$

54. Vijeth, S.; Sreelathakumary, I.; Rafeekher, M.; Kaushik, P. Appraisal of Genetics and Heterosis of Important Traits in Chilli Pepper Cultivated under the Influence of Chilli Leaf Curl Virus Disease. 2019.

55. Vijeth, S.; Dhaliwal, M.; Jindal, S.; Garg, N.; Kaushik, P.; Sharma, A. Diallel Analysis of Elite Tomato Lines Comprising Leaf Curl Virus Resistance Genes. Applied Ecology and Environmental Research 2019, 17, 6457-6471. 
56. Sunilkumar, P., M.K.,. Vijeth, S.,. Rathod, V.,. Kaushik Genetic Associations Analysis in Tomato (Solanum Lycopersicum L.) Involving Improved Germplasm Lines for Agronomic and Yield Contributing Traits. Int.J.Curr.Microbiol.App.Sci. 2019, 8, 2688-2702.

57. Sunilkumar, M. Genetic Divergence in Exotic Tomato (Solanum Lycopersicum L.) Genotypes Cultivated in Southern India.Journal of Pharmacognosy and Phytochemistry 2019, 8, 710-712.

58. Sinha, S.; Sandhu, K.; Bisht, N.; Naliwal, T.; Saini, I.; Kaushik, P. Ascertaining the Paradigm of Secondary Metabolism Enhancement through Gene Level Modification in Therapeutic Plants. Journal of Young Pharmacists 2019, 11, 337.

59. Saini, I.; Aggarwal, A.; Kaushik, P. Inoculation with Mycorrhizal Fungi and Other Microbes to Improve the Morpho-Physiological and Floral Traits of Gazania Rigens (L.) Gaertn. Agriculture 2019, 9, 51.

60. Saini, I.; Aggarwal, A.; Kaushik, P. Influence of Biostimulants on Important Traits of Zinnia Elegans Jacq. under Open Field Conditions. International Journal of Agronomy 2019, 2019.

61. Saini, D.K.; Kaushik, P. Visiting Eggplant from a Biotechnological Perspective: A Review. Scientia Horticulturae 2019, 253, 327-340.

62. Kaushik, P.; Saini, D.K. Silicon as a Vegetable Crops Modulator-A Review. Plants 2019, 8, 148.

63. Kaushik, P.; Saini, D.K. Sequence Analysis and Homology Modelling of SmHQT Protein, a Key Player in Chlorogenic Acid Pathway of Eggplant. bioRxiv 2019, 599282.

64. Kaushik, P.; Kumar, S. Data of de Novo Assembly of Fruit Transcriptome in Aegle Marmelos L. Data in brief 2019, 25, 104189. 
65. Kaushik, P. Standardisation of an Agroinfiltration Protocol for Eggplant Fruits and Proving Its Usefulness by Over-Expressing the SmHQT Gene. 2019.

66. Kaushik, P. Line x Tester Analysis for Morphological and Fruit Biochemical Traits in Eggplant (Solanum Melongena L.) Using Wild Relatives as Testers. Agronomy 2019, 9, 185.

67. Kaushik, P. Genetic Analysis for Fruit Phenolics Content, Flesh Color, and Browning Related Traits in Eggplant (Solanum Melongena). International journal of molecular sciences 2019, 20, 2990.

68. Kaushik, P. Application of Conventional, Biotechnological and Genomics Approaches for Eggplant (Solanum Melongena. L). Breeding with a Focus on Bioactive Phenolics. PhD Thesis, Universitat Politècnica de València, 2019.

69. Jain, B.; Sarial, A.; Kaushik, P.; others Understanding G\$times\$ E Interaction of Elite Basmati Rice (Oryza Sativa L.) Genotypes under North Indian Conditions Using Stability Models. Applied Ecology and Environmental Research 2019, 17, 5863-5885.

70. Devi, P.; Kaushik, P.; Saini, D.K. QTLs Identified for Biofortification Traits in Wheat: A Review. 2019.

71. Brar, N.S.; Kaushik, P.; Dudi, B.S. Assessment of Natural Ageing Related PhysioBiochemical Changes in Onion Seed. Agriculture 2019, 9, 163.

72. Tyagi, V.; Dhillon, S.; Kaushik, P. Stability Analysis of Some Novel Cytoplasmic Male Sterile Sources of Sunflower and Their Hybrids. Helia 2018, 41, 153-200.

73. Tyagi, V.; Dhillon, S.K.; Kaushik, P.; Kaur, G. Characterization for Drought Tolerance and Physiological Efficiency in Novel Cytoplasmic Male Sterile Sources of Sunflower (Helianthus Annuus L.). Agronomy 2018, 8, 232.

74. . 
75. Sharma, M.; Kaushik, P.; Chaturvedi, P. Enumeration, Antagonism and Enzymatic Activities of Microorganisms Isolated from Railway Station Soil. bioRxiv 2018, 454595. 76.

77. Kumar, P.; Bishnoi, S.; Kaushik, P. Genetic Variability, Heritability and Genetic Advance for Seed Yield and Other Agro-Morphological Traits in Faba Bean (Vicia Faba L.) Genotypes of Different Origin. Trends in Biosciences 2018, 10, 1246-1248.

78. Kaushik, P.; Plazas, M.; Prohens, J.; Vilanova, S.; Gramazio, P. Diallel Genetic Analysis for Multiple Traits in Eggplant and Assessment of Genetic Distances for Predicting Hybrids Performance. Plos One 2018, 13, e0199943.

79. Kaushik, P.; Kumar, S. Transcriptome Analysis of Bael (Aegle Marmelos L.) a Member of Family Rutaceae. bioRxiv 2018, 346403.

80. Kaushik, P.; Kumar, S. Transcriptome Analysis of Bael (Aegle Marmelos (L.) Corr.) a Member of Family Rutaceae. Forests 2018, 9, 450.

81. Kaushik, P.; Kumar, S. Data of de Novo Assembly of the Leaf Transcriptome in Aegle Marmelos. Data in brief 2018, 19, 700-703.

82. Kaushik, P.; Dhaliwal, M.S. Diallel Analysis for Morphological and Biochemical Traits in Tomato Cultivated under the Influence of Tomato Leaf Curl Virus. Agronomy 2018, 8, 153.

83. Dhaliwal, M.; Kaushik, P.; Kumar, S. Usefulness of Three under Exploited Vegetable Legumes - A Review. International Journal of Current Applied Sciences 2018, 7, 861870.

84. Rana, M.; Kaushik, P. Pigeon pea. In Vegetable Crops Science; CRC Press, 2017; pp. 715722. 
85. Kaushik, P.; Gramazio, P.; Vilanova, S.; Raigón, M.D.; Prohens, J.; Plazas, M. Phenolics Content, Fruit Flesh Colour and Browning in Cultivated Eggplant, Wild Relatives and Interspecific Hybrids and Implications for Fruit Quality Breeding. Food Research International 2017, 102, 392-401.

86. Kaushik, P.; Prohens, J.; Vilanova, S.; Gramazio, P.; Plazas, M. Phenotyping of Eggplant Wild Relatives and Interspecific Hybrids with Conventional and Phenomics Descriptors Provides Insight for Their Potential Utilization in Breeding. Frontiers in Plant Science 2016, 7, 677.

87. Kaushik, P.; Dhaliwal, M.S.; Jindal, S.K.; Srivastava, A.; Tyagi, V.; Brar, N.S.; Rana, M.K. Heterosis and Leaf Curl Virus Resistance in Rainy Season Tomato under North Indian Conditions. African Journal of Agricultural Research 2015, 10, 2763-2772.

88. Kaushik, P.; Andújar, I.; Vilanova, S.; Plazas, M.; Gramazio, P.; Herraiz, F.J.; Brar, N.S.; Prohens, J. Breeding Vegetables with Increased Content in Bioactive Phenolic Acids. Molecules 2015, 20, 18464-18481.

89. Jakhar, P.; Yogesh, O.; Janu, A.; Kaushik, P. Effect of Different Modes of Pollination on Quantitative and Qualitative Parameters of Radish Seed Crop. Trends in Biosci 2014, 7, 4041-4044.

90. Kumar, A.; Kumar, P.; Kumar, A.; others Study of Various Development Media for Standardization of Immature Embryo Culture in Capsicum Annuum L. Biosciences 2013, 237. 